\title{
Oropharyngeal aspiration: An alternative route for challenging in a mouse model of chemical-induced asthma ${ }^{\text {th }}$
}

\author{
Vanessa De Vooght ${ }^{\mathrm{a}}$, Jeroen A.J. Vanoirbeek ${ }^{\mathrm{a}}$, Steven Haenen ${ }^{\mathrm{a}}$, Erik Verbeken ${ }^{\mathrm{b}}$, \\ Benoit Nemery ${ }^{\mathrm{a}}$, Peter H.M. Hoet ${ }^{\mathrm{a}, *}$ \\ a Research Unit of Lung Toxicology, Katholieke Universiteit Leuven, Herestraat 49 bus 706, B-3000 Leuven, Belgium \\ b Department of Medical Diagnostic Sciences, Katholieke Universiteit Leuven, Leuven, Belgium
}

\section{A R T I C L E I N F O}

\section{Article history:}

Received 5 January 2009

Received in revised form 12 February 2009

Accepted 13 February 2009

Available online 28 February 2009

\section{Keywords:}

Toluene-2,4-diisocyanate

Occupational asthma

Murine model

Oropharyngeal aspiration

Skin

Draining lymph nodes

\begin{abstract}
A B S T R A C T
Background: To assess the importance of the route of challenge in an existing mouse model of chemicalinduced asthma, we replaced intranasal instillation by oropharyngeal aspiration. To our knowledge, oropharyngeal aspiration as a challenge route has not yet been investigated in a mouse model of chemicalinduced asthma.

Methods: On days 1 and 8, mice were dermally sensitized with toluene diisocyanate(TDI) (0.3\%) [or vehicle (acetone/olive oil)] and on day 15 they received a single challenge, via oropharyngeal aspiration, with TDI $(0.01 \%)$ or vehicle. One day after challenge, airway reactivity to methacholine was measured by a forced oscillation technique (FlexiVent) and total and differential cell counts, as well as levels of KC, IL-5, IL-17 and TNF- $\alpha$, were assessed in the bronchoalveolar lavage (BAL) fluid. Lymphocytes from the auricular and mediastinal lymph nodes were cultured to determine the concanavaline A-induced secretion of IL-2, IL-4, IL-10, IL-13, IL-17 and IFN- $\gamma$. Total serum IgE was measured.

Results: In TDI-sensitized mice, a significant increase in airway reactivity was found after a single oropharyngeal challenge with TDI. BAL neutrophils and eosinophils were increased 7 - and 5-fold, respectively. An upregulation of Th1 (IFN- $\gamma$ ), Th2 (IL-4, IL-10, IL-13) and Th17 (IL-17) cytokines was found in the auricular lymph nodes, in the mediastinal lymph nodes only IL-4 was upregulated. The total serum IgE level in TDI-sensitized mice was significantly increased when compared to control mice.

Conclusion: We conclude that challenging mice via oropharyngeal aspiration mimics the characteristics of human asthma well, without the possible drawbacks of other techniques.
\end{abstract}

(c) 2009 Elsevier Ireland Ltd. All rights reserved.

\section{Introduction}

Over the years there have been many efforts to develop animal models that mimic the phenotype of human asthma. Although the usefulness of animal models for studying human asthma has been heavily debated, the number of murine studies published, increases every year (Wenzel and Holgate, 2006). The use of mice is justified by the fact that the specific molecular pathways are similar to those of humans, and also because of their well-characterized

\footnotetext{
is The project was supported by a grant of the Interuniversity Attraction Pole Program, Belgian State, Belgian Science Policy P6/35 and from the 'Fonds voor Wetenschappelijk Onderzoek Vlaanderen' (FWO), FWO G.0547.08. JAJV is a post-doctoral fellow of the FWO.

* Corresponding author. Tel.: +32 163301 97; fax: +32 16347124 .

E-mail addresses: vanessa.devooght@med.kuleuven.be (V. De Vooght), jeroen.vanoirbeek@med.kuleuven.be (J.A.J. Vanoirbeek), steven.haenen@med.kuleuven.be (S. Haenen), erik.verbeken@med.kuleuven.be (E. Verbeken), ben.nemery@med.kuleuven.be (B. Nemery), peter.hoet@med.kuleuven.be (P.H.M. Hoet).
}

immune system, their fully sequenced genome, the existence of various genetically modified models and the availability of mousespecific reagents (Boverhof et al., 2008; Shapiro, 2006).

Because mice do not spontaneously exhibit symptoms consistent with asthma, they must be sensitized and challenged with an allergen or a chemical agent. Different techniques have been developed and optimized to trigger an immune response. Inhalation, intratracheal or intranasal instillation are widely used to administer agents to the respiratory tract. Each of these routes has specific advantages and disadvantages. Although inhalation is the most natural way of exposure, it is technically demanding, expensive and time-consuming and it requires large amounts of the test agent Exposure via intratracheal instillation has the advantage that exact amounts of test agent can be administered into the lung. However, this technique requires general anesthesia and some technical skill and it causes injury to the trachea, especially with repeated administrations (Rao et al., 2003). Intranasal application has gained popularity because it is an easy technique that can be used repeatedly. A disadvantage, however, is that the distribution between the upper and lower respiratory tracts is heavily influenced by 
the instilled volume, the degree of anesthesia and the nature of the vehicle in which the allergens are dissolved (aqueous or nonaqueous) (Ebino et al., 1999; Southam et al., 2002). Oropharyngeal aspiration has been proposed as an alternative to intratracheal instillation because it does not have the drawbacks of the latter. Thus, according to a recent study using silica particles, oropharyngeal aspiration results in less variability among animals and gives a more uniform pulmonary distribution of the test agent (Lakatos et al., 2006). To our knowledge, this route has not yet been investigated in chemical-induced asthma models.

In the past years, our research unit has developed a mouse model of chemical-induced (occupational) asthma (Tarkowski et al., 2007; Vanoirbeek et al., 2004, 2006, 2008). Using toluene-2,4diisocyanate (TDI), one of the most common causes of occupational asthma, we were able to mimic several characteristics of human asthma (Piirila et al., 2008). In this model, an intranasal challenge leads in previously sensitized animals to an early antigen-specific ventilatory response, bronchial hyper-responsiveness to methacholine $24 \mathrm{~h}$ later, and an airway inflammation, characterized mainly by neutrophils (Tarkowski et al., 2007; Vanoirbeek et al., 2004, 2006, 2008). Until now, mice were challenged by intranasal instillation in our mouse model. However, using this exposure route, questions arose on the relative roles of the upper and lower airways in the observed responses. To address this, we investigated whether we could obtain the same results found with intranasal instillation when bypassing the nose using oropharyngeal aspiration.

\section{Materials and methods}

\subsection{Reagents}

Toluene-2,4-diisocyanate (98\%; Fluka, CAS584-84-9), acetyl- $\beta$-methylcholine (methacholine) and acetone were obtained from Sigma-Aldrich (Bornem, Belgium). Pentobarbital (Nembutal ${ }^{\circledR}$ ) was obtained from Sanofi Santé Animale (CEVA, Brussels, Belgium) and Isoflurane (Forene ${ }^{\circledR}$ ) from Abbott Laboratories (S.A. Abbott N.V., Ottignies, Belgium). The vehicle (AOO) used to dissolve TDI consisted of a mixture of 2 volumes of acetone and 3 volumes of olive oil (Selection de Almazara, Carbonell, Madrid, Spain) for the dermal sensitization, and 1 volume of acetone and 4 volumes of olive oil for the challenge. Concentrations of TDI are given as percent $(v / v)$ in AOO.

\subsection{Animals}

Male BALB/c mice (approximately $20 \mathrm{~g}$, 6 weeks old) were obtained from Harlan (Horst, The Netherlands). The mice were housed in a conventional animal house with 12-h dark/light cycles. They were housed in filter top cages and received lightly acidified water and pelleted food (Trouw Nutrition, Gent, Belgium) ad libitum. All experimental procedures were approved by the Local Ethical Committee for Animal Experiments.

\subsection{Treatment protocol}

On days 1 and 8 the animals were dermally treated with $0.3 \%$ TDI or with the vehicle on the dorsum of both ears $(20 \mu \mathrm{l} / \mathrm{ear})$. On day 15 the mice underwent, under light isoflurane anesthesia, an oropharyngeal aspiration $(20 \mu \mathrm{l})$ of $0.01 \%$ TDI or vehicle. The oropharyngeal aspiration technique was modified from the article by Lakatos et al. (2006). Briefly, the anesthetized mice were held vertically and the tongue was gently pulled out of the mouth using forceps (Fig. 1). The liquid was pipetted onto the back of the tongue while the nose was closed, thus forcing the mice to breathe through the mouth. The nose and tongue were released after at least two breaths had been completed. Each treatment group consisted of 10-15 animals.

The mice were sacrificed $24 \mathrm{~h}$ after the challenge. Experimental groups are AOO/AOO, AOO/TDI and TDI/TDI. The first abbreviation identifies the agent used for the dermal application on days 1 and 8 (sensitization) and the second abbreviation identifies the agents administered via oropharyngeal aspiration on day 15 (challenge).

\subsection{Ventilatory function}

\subsubsection{Early ventilatory response and airway reactivity to methacholine}

Before the challenge, the ventilatory function of each mouse was first recorded, in resting condition and unrestrained, for $5 \mathrm{~min}$ in a whole body plethysmograph (EMKA Technologies, Paris, France). Immediately after the oropharyngeal aspiration, mice were placed again in the whole body plethysmograph (zero time point) and their ventilatory parameters were measured for $40 \mathrm{~min}$. Every $30 \mathrm{~s}$, the mean enhanced pause (Penh), which is a composite index indicative of airway obstruction, was calculated. The area under the curve (AUC) of Penh against time between 0 and 40 min was calculated for each individual mouse and this figure was used for statistical analysis.

Twenty-four hours after the challenge, airway hyper-reactivity (AHR) to methacholine was assessed using a forced oscillation technique (FlexiVent, SCIREQ Montreal, Canada). Mice were anesthetized with an intraperitoneal injection of pentobarbital $(70 \mathrm{mg} / \mathrm{kg})$. The trachea was exposed and an 18 -gauge metal needle was inserted into the trachea. Mice were connected to a computer-controlled small animal ventilator, and quasi-sinusoidally ventilated with a tidal volume of $10 \mathrm{ml} / \mathrm{kg}$ at a frequency of 150 breaths/min and a positive end-expiratory pressure of $2 \mathrm{~cm} \mathrm{H}_{2} \mathrm{O}$ to achieve a mean lung volume close to that during spontaneous breathing. After measurement of a baseline, each mouse was challenged with methacholine aerosol, generated with an in-line nebulizer and administered directly through the ventilator for $5 \mathrm{~s}$, with increasing concentrations $(0,0.625,1.25,2.5,5$ and $10 \mathrm{mg} / \mathrm{ml})$. Airway resistance $(R)$ was measured using a "snapshot" protocol each $20 \mathrm{~s}$ for $2 \mathrm{~min}$. The mean of these six values was used for each methacholine concentration, unless the COD (coefficient of determination) of a measurement was smaller than 0.95 . For each mouse, $R$ was plotted against methacholine concentration (from 0 to $10 \mathrm{mg} / \mathrm{ml}$ ) and the AUC was calculated.

\subsection{Pulmonary inflammation (bronchoalveolar lavage)}

After measuring airway reactivity to methacholine the mice were deeply anesthetized by an intraperitoneal injection of pentobarbital $(90 \mathrm{mg} / \mathrm{kg}$ body weight). Blood was first taken from the retro-orbital plexus, centrifuged $(14,000 \times \mathrm{g}, 10 \mathrm{~min})$ and serum samples were stored for further analyses. Afterwards, mice were killed by section of the abdominal vessels. The lungs were lavaged, in situ, three times with $0.7 \mathrm{ml}$ sterile saline $(0.9 \% \mathrm{NaCl})$, and the recovered fluid was pooled. Cells were counted using a Bürker hemocytometer (total cells) and the bronchoalveolar lavage $(\mathrm{BAL})$ fluid was centrifuged $(1000 \times \mathrm{g}, 10 \mathrm{~min})$. The supernatant was frozen $\left(-80^{\circ} \mathrm{C}\right)$ until further analyses. For differential cell counts, $250 \mu \mathrm{l}$ of the resuspended cells $(100,000$ cells $/ \mathrm{ml})$ were spun $(300 \times g, 6 \mathrm{~min})$ (Cytospin 3, Shandon, TechGen, Zellik, Belgium) onto microscope slides, air-dried and stained (Diff-Quik ${ }^{\circledR}$ method, Medical Diagnostics, Düdingen, Germany). For each sample, 200 cells were counted for the number of macrophages, eosinophils, neutrophils and lymphocytes.

The level of interleukin (IL) 17 was measured in undiluted BAL fluid by a sandwich enzyme-linked immunosorbent assay (ELISA), according to the manufacturer's instructions (R\&D Systems, Abingdon, UK). Levels of IL-5, cytokine-induced neutrophil chemoattractant $(\mathrm{KC})$ and tumor necrosis factor alpha (TNF- $\alpha$ ) were measured via Cytometric Bead Array and analyzed with the FCAP Array Software
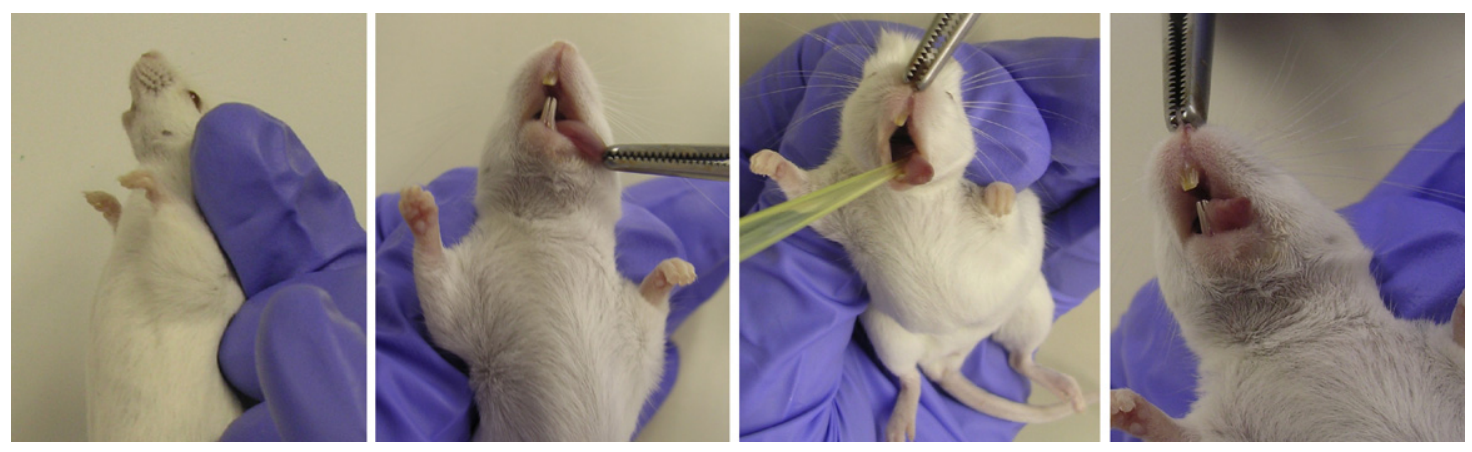

Fig. 1. Oropharyngeal aspiration technique. The different steps in oropharyngeal aspiration are shown. 

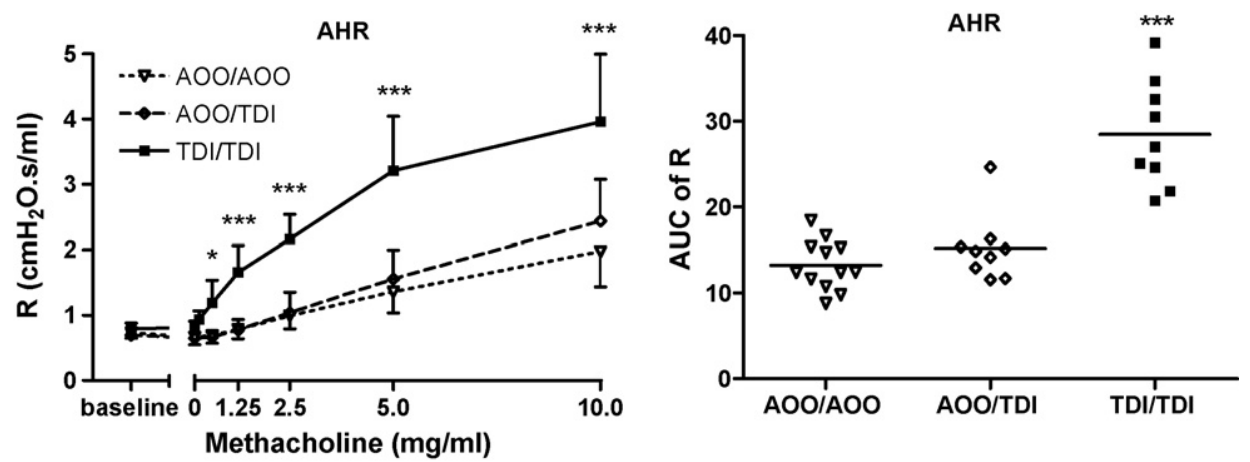

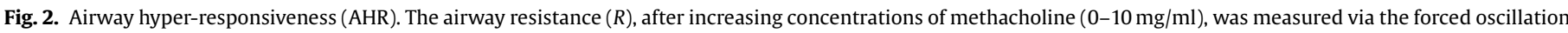

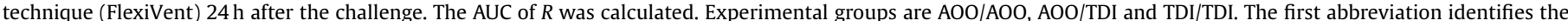

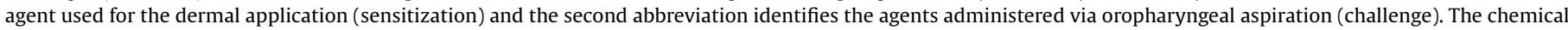

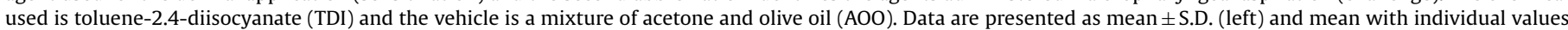
(right), $n=9-12$ per group. ${ }^{*} p<0.05$ and ${ }^{* * *} p<0.001$ compared with the AOO/AOO group.

(BD Biosciences, Erembodegem, Belgium) on the FACSArray (BD Biosciences, Erembodegem, Belgium).

After taking BAL fluid, the lungs were instilled with $4 \%$ formaldehyde until full inflation of all lobes, as judged visually. Evaluation of lung injury on slides stained by hematoxylin and eosin (H\&E) was performed by an experienced pathologist in a blinded manner.

\subsection{Lymph node cells (LNC)}

Retro-auricular and mediastinal lymph nodes were obtained from the same mice. The retro-auricular lymph nodes were processed for each mouse separately, while the mediastinal lymph nodes from two to three mice were pooled. The lymph nodes were kept on ice in RPMI-1640 (Invitrogen, Merelbeke, Belgium) and cell suspensions were obtained by pressing the lymph nodes through a cell strainer $(100 \mu \mathrm{m})($ BD Bioscience, Erembodegem, Belgium) and rinsing with $10 \mathrm{ml}$ tissue culture medium (RPMI-1640). Cells were counted using a Bürker hemocytometer. Lymphocytes were washed three times and suspended $\left(10^{7}\right.$ cells $\left./ \mathrm{ml}\right)$ in complete tissue culture medium (RPMI-1640 supplemented with 10\% heat-inactivated fetal bovine serum, $10 \mathrm{mg} / \mathrm{ml}$ streptomycin, $100 \mathrm{IU} / \mathrm{ml}$ penicillin, $1 \mathrm{mM}$ sodium pyruvate).

Five-hundred thousand cells were stained with anti-CD3 ${ }^{+}$(APC), anti-CD4 ${ }^{+}$ (APC-Cy7), anti-CD8 ${ }^{+}$(PerCP-Cy5.5) and anti-CD25 ${ }^{+}$(PE), or received a single staining with anti-CD19 ${ }^{+}(\mathrm{PE})$ labeled antibodies, according to standard procedures, and with control samples being labeled with isotype match control antibodies (BD Biosciences, Erembodegem, Belgium). Flow cytometry (Facsarray, BD Biosciences, Erembodegem, Belgium) was performed using at least $10^{5}$ cells.

Cells were seeded into 48 -well culture plates at a density of $10^{6}$ cells $/ \mathrm{ml}$ and incubated in complete RPMI-1640 medium for $42 \mathrm{~h}$ without or with $2.5 \mu \mathrm{g} / \mathrm{ml}$ of concanavaline A (ConA) (Sigma-Aldrich, Bornem, Belgium). Cells were then centrifuged $(1000 \times g, 10 \mathrm{~min})$ and supernatants were stored at $-80^{\circ} \mathrm{C}$. The level of IL-17 was measured in undiluted BAL fluid by an ELISA, according to the manufacturer's instructions (R\&D Systems, Abingdon, UK). Levels of IL-2, IL-4, IL-10, IL-12, IL-13 and interferon gamma (IFN- $\gamma$ ) were measured via Cytometric Bead Array and analyzed with the FCAP Array Software (BD Biosciences, Erembodegem, Belgium) on the FACSArray (BD Biosciences, Erembodegem, Belgium).

\subsection{Total serum $\operatorname{IgE}$}

The OptEIA ${ }^{\mathrm{TM}}$ Mouse IgE set from Pharmingen (BD Biosciences, Erembodegem, Belgium) was used to measure total serum IgE (diluted 1/70). Measurements were performed according to the manufacturer's instructions.

\subsection{Statistical analysis}

Data are shown as means and standard deviations (S.D.). AHR data were analyzed using a two-way ANOVA, while the AUC of $R$ was analyzed with a one-way ANOVA followed by a Bonferroni test. The differential cell counts as well as the concentrations of the different cytokines were analyzed with a non-parametric Kruskal-Wallis test followed by a Dunn's multiple comparison test (Graphpad Prism 4.01, Graphpad Software Inc, San Diego, USA). A level of $p<0.05$ (two-tailed) was considered significant.

\section{Results}

The early response, immediately after challenge, measured in the whole body plethysmograph after the oropharyngeal challenge showed no statistically significant differences in Penh between the
TDI/TDI group (mean AUC $31 \pm 14$ ) and the control groups AOO/AOO (mean AUC $21 \pm 12$ ) and AOO/TDI (mean AUC 16 \pm 2 ).

Fig. 2 shows airway resistance, measured by the FlexiVent, after increasing concentrations of methacholine, $24 \mathrm{~h}$ after the challenge. A significant 2-fold higher airway hyper-responsiveness (AHR) was found in the TDI/TDI group compared to the controls.

Numbers of macrophages, neutrophils, eosinophils and lymphocytes were assessed in the BAL fluid (Fig. 3). Significantly higher amounts of neutrophils and eosinophils and lower amounts of macrophages were found after dermal sensitization and challenge with TDI

Fig. 4 shows a histological view of the lungs centered on a large airway, $24 \mathrm{~h}$ after challenging with vehicle (Fig. $4 \mathrm{~A}$ and $\mathrm{B}$ ) or TDI (Fig. 4C and D). Control animals (AOO/AOO) showed no signs of inflammation. The lungs of TDI-sensitized and TDI-challenged animals showed an influx of neutrophils, epithelial necrosis and epithelial shedding.

A 7-fold increase in total serum IgE concentration was found in the TDI/TDI $(1217 \pm 493 \mathrm{ng} / \mathrm{ml})$ group compared to AOO/AOO $(181 \pm 76 \mathrm{ng} / \mathrm{ml})$ and AOO/TDI $(144 \pm 37 \mathrm{ng} / \mathrm{ml})$.

Table 1 shows different cytokines measured in the BAL fluid. There were no significant differences in concentrations of the neutrophil attractants KC, IL-17, the eosinophil chemo-attractant IL-5, or TNF- $\alpha$ between the TDI/TDI group and the controls.

The different subpopulations of lymphocytes $\left(\mathrm{CD} 3^{+} \mathrm{CD} 4^{+}\right.$, $\mathrm{CD}^{+} \mathrm{CD}^{+} \mathrm{CD}^{2} 5^{+}, \mathrm{CD}^{+}{ }^{+} \mathrm{CD} 8^{+}$and $\mathrm{CD} 19^{+}$) characterized with the FACSarray showed for the auricular lymph nodes similar results compared to our previous publications (Tarkowski et al., 2007). We found a significant increase in the total amount of $\mathrm{CD}^{+} \mathrm{CD}^{+}$, $\mathrm{CD}^{+} \mathrm{CD}^{+} \mathrm{CD}^{2} 5^{+}, \mathrm{CD}^{+}{ }^{+} \mathrm{CD} 8^{+}$and $\mathrm{CD} 19^{+}$lymphocytes in the auric-

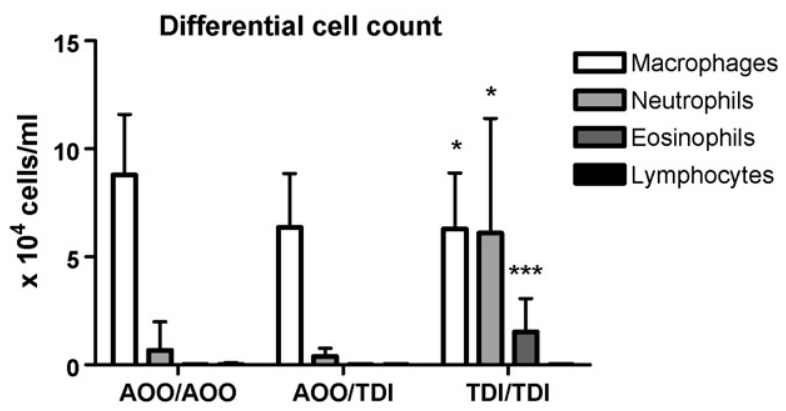

Fig. 3. Differential cell count in BAL after oropharyngeal aspiration. Total numbers of macrophages, neutrophils, eosinophils and lymphocytes were determined in the BAL fluid $24 \mathrm{~h}$ after challenging with the vehicle or TDI. Experimental groups are identical to Fig. 2. Data are presented as mean \pm S.D., $n=9-15$ per group. ${ }^{*} p<0.05$, ${ }^{* * *} p<0.001$ compared with the $\mathrm{AOO} / \mathrm{AOO}$ group. 
(A)

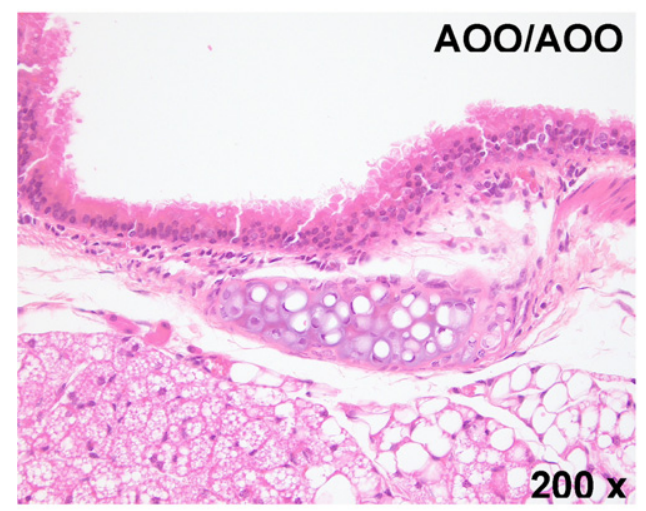

(B)

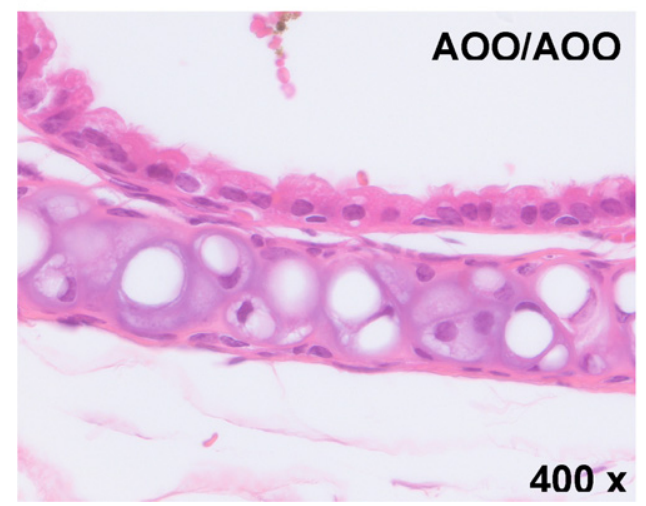

(C)

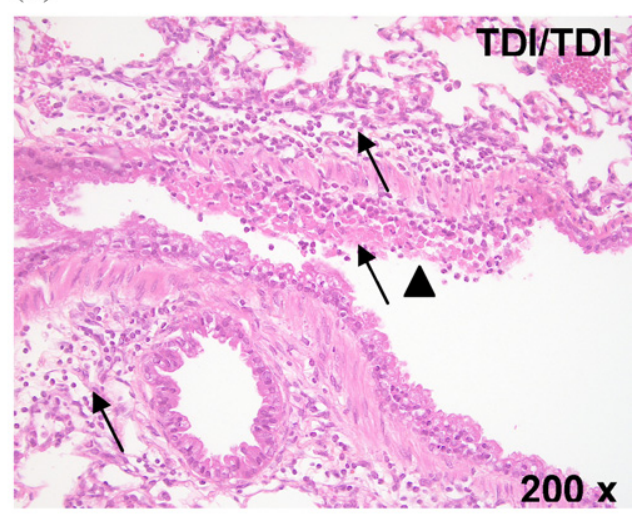

(D)

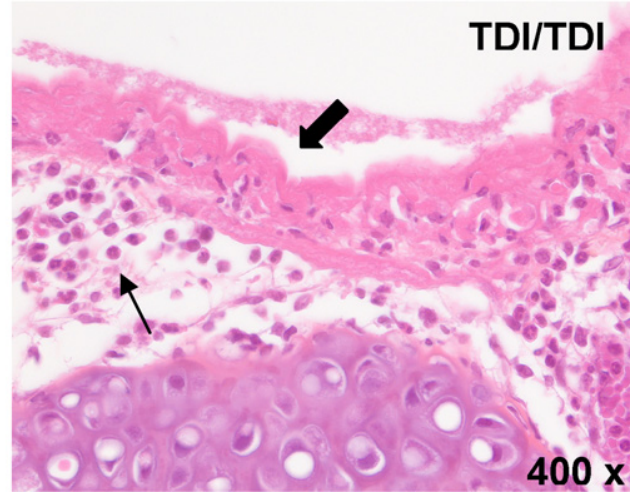

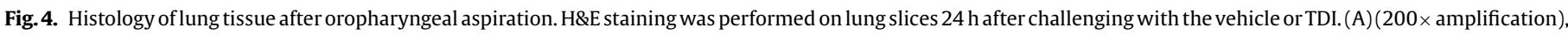

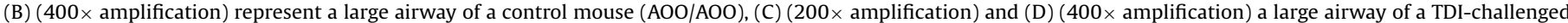
mouse. $(\rightarrow$ ) Inflammation (mainly neutrophils), $(\bullet)$ epithelial shedding and $(\rightarrow$ ) epithelial necrosis.

Table 1

Cytokines in the bronchoalveolar lavage.

\begin{tabular}{lccc}
\hline & AOO/AOO & AOO/TDI & TDI/TDI \\
\hline KC $(\mathrm{pg} / \mathrm{ml})$ & $7.7 \pm 3.2$ & $12.3 \pm 10.6$ & $11.9 \pm 8.0$ \\
IL-17 $(\mathrm{pg} / \mathrm{ml})$ & $54.8 \pm 52.3$ & $30.4 \pm 41.0$ & $35.3 \pm 32.5$ \\
IL-5 $(\mathrm{pg} / \mathrm{ml})$ & $2.9 \pm 0.5$ & $3.3 \pm 1.5$ & $8.3 \pm 6.9$ \\
TNF- $\alpha(\mathrm{pg} / \mathrm{ml})$ & $9.2 \pm 2.9$ & $12.2 \pm 5.6$ & $8.3 \pm 4.5$ \\
\hline
\end{tabular}

Concentrations of KC, IL-17, IL-5 and TNF- $\alpha$ were measured, via Cytometric Bead Array, in BAL $24 \mathrm{~h}$ after challenge with TDI or vehicle. Experimental groups are identical to Fig. 2. Data are presented as mean \pm S.D. and $n=9-15$ per group.

ular lymph nodes. In the mediastinal lymph nodes, we found no differences in subpopulations of lymphocytes between the different groups (data not shown).

Table 2(A) and (B) shows the concentrations of cytokines typical for T-helper (Th) 1 (IL-2, IL-12, IFN- $\gamma$ ), Th2 (IL-4, IL-10, IL-13) and Th17 (IL-17) as measured in the supernatants of auricular and mediastinal lymph nodes after culturing for $42 \mathrm{~h}$ with Con $\mathrm{A}$. The spontaneous release of cytokines in the supernatants of cultured lymphocytes was too low to be detected. Significantly higher IL-4 concentrations in the auricular as well as in the mediastinal lymphocytes were found in the TDI/TDI group. Significantly higher amounts were found in the auricular lymphocytes for IL-10, IL-13, IL-17 and IFN- $\gamma$ concentrations after dermal sensitization and challenge with TDI. IL-12 concentrations were below the detection limit (data not shown).

\section{Discussion}

In this paper we aimed to further validate our mouse model by introducing oropharyngeal aspiration as a challenge technique.
This route of challenge proved to reproduce all our previous findings using intranasal challenge, except for the increase in Penh immediately following challenge. A significant increase in airway responsiveness was found after TDI challenge, as well as an influx of neutrophils and eosinophils in the BAL fluid.

Oropharyngeal aspiration has been proposed as an easy alternative to expose the lungs to different substances but, to

Table 2

Cytokines in supernatant of auricular (A) and mediastinal (B) lymph nodes.

\begin{tabular}{|c|c|c|c|}
\hline & $\mathrm{AOO} / \mathrm{AOO}$ & AOO/TDI & TDI/TDI \\
\hline \multicolumn{4}{|c|}{ (A) Auricular lymph nodes } \\
\hline $\mathrm{IL}-2(\mathrm{pg} / \mathrm{ml})$ & $224.4 \pm 143.5$ & $219.3 \pm 72.2$ & $143.2 \pm 100.0$ \\
\hline $\mathrm{IL}-4(\mathrm{pg} / \mathrm{ml})$ & $0.5 \pm 0.6$ & $1.2 \pm 0.7$ & $17.0 \pm 5.2^{* * *}$ \\
\hline $\mathrm{IL}-10(\mathrm{pg} / \mathrm{ml})$ & $18.8 \pm 14.1$ & $29.6 \pm 34.3$ & $183.5 \pm 84.4^{* * *}$ \\
\hline IL-13 (pg/ml) & $3.8 \pm 3.3$ & $2.0 \pm 1.5$ & $116.8 \pm 48.9^{* * *}$ \\
\hline IL-17 (pg/ml) & $447.6 \pm 259.0$ & $1432 \pm 1038$ & $1437 \pm 1036^{*}$ \\
\hline IFN- $\gamma(\mathrm{pg} / \mathrm{ml})$ & $57.9 \pm 41.4$ & $213.9 \pm 168.4$ & $348.3 \pm 156.6^{* * *}$ \\
\hline \multicolumn{4}{|c|}{ (B) Mediastinal lymph nodes } \\
\hline $\mathrm{IL}-2(\mathrm{pg} / \mathrm{ml})$ & $37.8 \pm 36.1$ & $29.7 \pm 23.8$ & $67.4 \pm 34.1$ \\
\hline $\mathrm{IL}-4(\mathrm{pg} / \mathrm{ml})$ & $0.5 \pm 0.6$ & $0.2 \pm 0.1$ & $3.8 \pm 1.9^{*}$ \\
\hline $\mathrm{IL}-10(\mathrm{pg} / \mathrm{ml})$ & $4.8 \pm 0.0$ & $14.0 \pm 13.2$ & $20.8 \pm 14.4$ \\
\hline IL-13 (pg/ml) & $1.2 \pm 0.0$ & $1.2 \pm 0.0$ & $16.3 \pm 21.6$ \\
\hline IL-17 (pg/ml) & $17.2 \pm 0.5$ & $30.8 \pm 31.2$ & $106.5 \pm 103.7$ \\
\hline IFN- $\gamma(\mathrm{pg} / \mathrm{ml})$ & $8.2 \pm 6.9$ & $8.4 \pm 9.6$ & $38.5 \pm 30.8$ \\
\hline
\end{tabular}

The auricular lymph nodes were processed for each mice separately, while the mediastinal lymph nodes of two to three mice were pooled and the obtained lymph node cells were cultured ( $42 \mathrm{~h}$ ) with concanavaline A (ConA, $2.5 \mu \mathrm{g} / \mathrm{ml})$. IL-2, IL-4, IL-10, IL-13, IL-17 and IFN- $\gamma$ were measured, via Cytometric Bead Array, in supernatant. Experimental groups are identical to Fig. 2. Data are presented as mean \pm S.D.

$p<0.05$ compared to the AOO/AOO group.

*** $p<0.001$ compared to the AOO/AOO group. 
our knowledge, oropharyngeal aspiration has not been used in chemical-induced asthma research. Foster et al. (2001) used the aspiration technique for the measurement of mucociliary function by using ${ }^{99 \mathrm{~m}}$ Tc-labeled sulfide colloid and later Rao et al. (2003), Lakatos et al. (2006) and Morgan et al. (2008) used it for exposing mice to particles, a silica suspension or to test respiratory toxicity of diacetyl, respectively (Fairley et al., 2007; Foster et al., 2001; Lakatos et al., 2006; Morgan et al., 2008; Rao et al., 2003). KeanMyers et al. determined the tissue distribution after oropharyngeal aspiration using Evan's blue dye. The authors observed none of the dye in the stomach, only a small amount in the trachea and the remainder of the dye in the lungs (Keane-Myers et al., 1998). Foster et al. used ${ }^{99 \mathrm{~m}}$ Tc-labeled sulfide colloid to quantify the deposition to the lungs. They found that the amount in the lung was comparable to that achieved with intratracheal instillation but it appeared to be volume dependent. Aspiration delivered on average $62 \pm 2 \%$ (S.E.) to the lung using $25 \mu \mathrm{l}$ and $81 \pm 2 \%$ using $50 \mu \mathrm{l}$ of ${ }^{99 \mathrm{~m}}$ Tc-labeled sulfide colloid (Foster et al., 2001). In unpublished experiments we also used Evan's blue dye and found similar results as Kean-Myers et al., although we did find some exposures of the stomach.

We experienced also some difficulties to find the correct nonaqueous vehicle for the oropharyngeal aspiration technique. When using intranasal instillation as a challenge technique, we used a mixture of 2 volumes of acetone and 3 volumes of olive oil. In preliminary experiments (data not shown), this type of vehicle produced pulmonary inflammation when given via oropharyngeal aspiration. So, we changed the composition to 1 volume of acetone and 4 volumes of olive oil. Although this still led to some background inflammation in our control groups, we found pronounced differences between mice challenged with vehicle vs. TDI.

A concentration of $0.1 \% \mathrm{TDI}$, as previously used for challenging via intranasal instillation, caused too much mucosal irritation when given via oropharyngeal aspiration. Decreasing the concentration to $0.01 \%$ TDI gave no signs of irritation and was, therefore, further used in the experiments.

In previous experiments we used intranasal instillation as a challenge technique. Although it is an easy and quick technique, it mainly exposes the nose and upper airways. Introducing oropharyngeal aspiration gave us the opportunity to further develop our mouse model and to compare both techniques. Table 3 gives a summary of the similarities and differences in the results obtained after intranasal instillation and after oropharyngeal aspiration.

Earlier publications of our research unit concluded that a single challenge with TDI, via intranasal instillation, gave an early ventilatory response (increased Penh) in previously sensitized animals. This early response, however, was not so pronounced with oropharyngeal challenge. This indicates that the early ventilatory changes found after intranasal instillation with TDI may be mainly caused by a nasal response measured by the whole body plethysmograph. This confirms that nasal responses can have an important influence on the measurements obtained with the whole body plethysmograph and that this has to be taken into account when using this device. On the other hand, the findings show that the nose and upper airways are important target organs to initiate an early response and this may be relevant for chemical-induced rhinitis.

With oropharyngeal aspiration we found, as before with intranasal challenge, a pronounced airway hyper-responsiveness in the TDI-sensitized and TDI-challenged mice, along with increases in total amounts of neutrophils and eosinophils in the BAL fluid. The migration of these inflammatory cells towards the lungs appeared to be regulated by the cytokines KC and IL-5 (Cieslewicz et al., 1999; McKinley et al., 2005). Surprisingly we did not find an increase in IL17 in BAL, although it is known that IL-17 also plays an important role in recruiting neutrophils to the airways through its stimula-
Table 3

Comparison between intranasal instillation and oropharyngeal aspiration technique.

\begin{tabular}{|c|c|c|}
\hline & Intranasal instillation & Oropharyngeal aspiration \\
\hline \multicolumn{3}{|l|}{ Sensitization } \\
\hline Concentration TDI & $0.3 \%$ & $0.3 \%$ \\
\hline Vehicle & $\mathrm{AOO}(2: 3)$ & $\mathrm{AOO}(2: 3)$ \\
\hline \multicolumn{3}{|l|}{ Challenge } \\
\hline Concentration TDI & $0.1 \%$ & $0.01 \%$ \\
\hline Vehicle & $\mathrm{AOO}(2: 3)$ & $\mathrm{AOO}(1: 4)$ \\
\hline \multicolumn{3}{|l|}{ Airway response } \\
\hline Early response (Penh) & +++ & $\sim$ \\
\hline Airway hyper-reactivity & ++ & +++ \\
\hline \multicolumn{3}{|l|}{ Inflammation (BAL) } \\
\hline & Neutrophils & Neutrophils/eosinophils \\
\hline \multicolumn{3}{|c|}{ Lymph nodes: cell subpopulations } \\
\hline Auricular LN & ++ & ++ \\
\hline Mediastinal LN & & $\sim$ \\
\hline
\end{tabular}

This table compares the different parameters measured in our mouse model of chemical-induced asthma between challenging by intranasal instillation or oropharyngeal aspiration. +++ increase with $p<0.001,++$ increase with $p<0.01,+$ increase with $p<0.05, \sim$ no significant difference compared to the AOO/AOO group. A blank cell means that we did not measure this parameter in the experiment. The data shown with the intranasal instillation technique have been published by Vanoirbeek et al. (2008).

tory effects on neutrophil mobilizing cytokines such as IL-6 and IL-8 (Linden, 2001; Schmidt-Weber et al., 2007). IL-17 is mainly produced by T-lymphocytes and our lack of lymphocytes in the BAL fluid can possibly explain the absence of this cytokine in our experiments. Previously, using intranasal instillation as a challenge technique, we found a lung inflammation mainly characterized by neutrophils. It is well known that besides neutrophils, eosinophils are prominent in the inflammation process of allergic asthma. A broad correlation between clinical asthma severity and the degree of airway eosinophilia has been recorded (Holgate, 2008). By using oropharyngeal aspiration we were able to obtain another characteristic of human asthma, i.e. recruitment of eosinophils to the lungs.

Cytokines measured in the supernatants of auricular and mediastinal lymph node cells were of a mixed Th1-Th2 response, as previously described by ourselves and other research groups (Matheson et al., 2005a,b; Tarkowski et al., 2007; Vanoirbeek et al., 2008). Although cytokines of both cell types were present, the Th2 profile dominated with increases in IL-4, IL-10 and IL-13, whereas IFN- $\gamma$ was the only up-regulated Th1 cytokine. An increase in $\mathrm{CD}^{+} \mathrm{CD} 25^{+} \mathrm{T}$-regulatory lymphocytes (data not shown) was followed by increases in IL-10 in TDI challenged mice. IL-10 is one of the immunosuppressive cytokines identified and appears to play an important role in natural tolerance (Botturi et al., 2007). There are indications that the number and/or function of the T-regulatory population can be impaired in patients affected by allergic diseases (Bacchetta et al., 2007). We found an increase instead of a decrease in $\mathrm{CD} 4^{+} \mathrm{CD} 25^{+}$, but as found by other researchers, T-regulatory lymphocytes have different levels of activity in mouse strains that are susceptible or resistant to the development of asthma (Lewkowich et al., 2005).

In conclusion, we have further refined a method to induce chemical-induced asthma in a mouse model. Oropharyngeal aspiration as a challenge technique has proven that it mimics the characteristics of human asthma well without the disadvantages of other techniques. This technique has improved our model and this will lead to a better understanding of the mechanisms of chemicalinduced asthma.

\section{Conflict of interest}

None declared. 


\section{References}

Bacchetta, R., Gambineri, E., Roncarolo, M.G., 2007. Role of regulatory T cells and FOXP3 in human diseases. J. Allergy Clin. Immunol. 120 (2), 227-235.

Botturi, K., Vervloet, D., Magnan, A., 2007. T cells and allergens relationships: are they that specific? Clin. Exp. Allergy 37 (8), 1121-1123.

Boverhof, D.R., Billington, R., Gollapudi, B.B., Hotchkiss, J.A., Krieger, S.M., Poole, A., Wiescinski, C.M., Woolhiser, M.R., 2008. Respiratory sensitization and allergy: current research approaches and needs. Toxicol. Appl. Pharmacol. 226 (1), $1-13$.

Cieslewicz, G., Tomkinson, A., Adler, A., Duez, C., Schwarze, J., Takeda, K., Larson, K.A., Lee, J.J., Irvin, C.G., Gelfand, E.W., 1999. The late, but not early, asthmatic response is dependent on IL-5 and correlates with eosinophil infiltration. J. Clin. Invest. 104 (3), 301-308.

Ebino, K., Lemus, R., Karol, M.H., 1999. The importance of the diluent for airway transport of toluene diisocyanate following intranasal dosing of mice. Inhal. Toxicol. 11 (3), 171-185.

Fairley, K.J., Purdy, R., Kearns, S., Anderson, S.E., Meade, B.J., 2007. Exposure to the immunosuppressant, perfluorooctanoic acid, enhances the murine IgE and airway hyperreactivity response to ovalbumin. Toxicol. Sci. 97 (2), 375-383.

Foster, W.M., Walters, D.M., Longphre, M., Macri, K., Miller, L.M., 2001. Methodology for the measurement of mucociliary function in the mouse by scintigraphy. J. Appl. Physiol. 90 (3), 1111-1117.

Holgate, S.T., 2008. Pathogenesis of asthma. Clin. Exp. Allergy 38 (6), 872-897.

Keane-Myers, A.M., Gause, W.C., Finkelman, F.D., Xhou, X.D., Wills-Karp, M., 1998 Development of murine allergic asthma is dependent upon B7-2 costimulation. J. Immunol. 160 (2), 1036-1043.

Lakatos, H.F., Burgess, H.A., Thatcher, T.H., Redonnet, M.R., Hernady, E., Williams, J.P., Sime, P.J., 2006. Oropharyngeal aspiration of a silica suspension produces a superior model of silicosis in the mouse when compared to intratracheal instillation. Exp. Lung Res. 32 (5), 181-199.

Lewkowich, I.P., Herman, N.S., Schleifer, K.W., Dance, M.P., Chen, B.L., Dienger, K.M., Sproles, A.A., Shah, J.S., Kohl, J., Belkaid, Y., Wills-Karp, M., 2005. CD4+CD25+ T cells protect against experimentally induced asthma and alter pulmonary dendritic cell phenotype and function. J. Exp. Med. 202 (11), 1549-1561.

Linden, A., 2001. Role of interleukin-17 and the neutrophil in asthma. Int. Arch. Allergy Immunol. 126 (3), 179-184.

Matheson, J.M., Johnson, V.J., Luster, M.I., 2005a. Immune mediators in a murine model for occupational asthma: studies with toluene diisocyanate. Toxicol. Sci. 84 (1), 99-109.
Matheson, J.M., Johnson, V.J., Vallyathan, V., Luster, M.I., 2005b. Exposure and immunological determinants in a murine model for toluene diisocyanate (TDI) asthma. Toxicol. Sci. 84 (1), 88-98.

McKinley, L., Kim, J., Bolgos, G.L., Siddiqui, J., Remick, D.G., 2005. CXC chemokines modulate IgE secretion and pulmonary inflammation in a model of allergic asthma. Cytokine 32 (3-4), 178-185.

Morgan, D.L., Flake, G.P., Kirby, P.J., Palmer, S.M., 2008. Respiratory toxicity of diacetyl in C57BL/6 mice. Toxicol. Sci. 103 (1), 169-180.

Piirila, P.L., Meuronen, A., Majuri, M.L., Luukkonen, R., Mantyla, T., Wolff, H.J., Nordman, H., Alenius, H., Laitinen, A., 2008. Inflammation and functional outcome in diisocyanate-induced asthma after cessation of exposure. Allergy 63 (5), 583-591.

Rao, G.V., Tinkle, S., Weissman, D.N., Antonini, J.M., Kashon, M.L., Salmen, R., Battelli, L.A., Willard, P.A., Hoover, M.D., Hubbs, A.F., 2003. Efficacy of a technique for exposing the mouse lung to particles aspirated from the pharynx. J. Toxicol. Environ. Health A 66 (15), 1441-1452.

Schmidt-Weber, C.B., Akdis, M., Akdis, C.A., 2007. TH17 cells in the big picture of immunology. J. Allergy Clin. Immunol. 120 (2), 247-254.

Shapiro, S.D., 2006. Animal models of asthma: proallergic avoidance of animal (model[s]) is not an option. Am. J. Respir. Crit. Care Med. 174 (11), 1171-1173.

Southam, D.S., Dolovich, M., O'Byrne, P.M., Inman, M.D., 2002. Distribution of intranasal instillations in mice: effects of volume, time, body position, and anesthesia. Am. J. Physiol. Lung Cell Mol. Physiol. 282 (4), L833-L839.

Tarkowski, M., Vanoirbeek, J.A.J., Vanhooren, H.M., De Vooght, V., Mercier, C., Ceuppens, J.L., Nemery, B., Hoet, P.M.H., 2007. Immunological determinants of ventilatory changes induced in mice by dermal sensitization and respiratory challenge with toluene diisocyanate. Am. J. Physiol. Lung Cell Mol. Physiol. 292, L207-L214.

Vanoirbeek, J.A., De Vooght, V., Vanhooren, H.M., Nawrot, T.S., Nemery, B., Hoet, P.H., 2008. How long do the systemic and ventilatory responses to toluene diisocyanate persist in dermally sensitized mice? J. Allergy Clin. Immunol. 121, 456-463.

Vanoirbeek, J.A., Tarkowski, M., Ceuppens, J.L., Verbeken, E.K., Nemery, B., Hoet, P.H., 2004. Respiratory response to toluene diisocyanate depends on prior frequency and concentration of dermal sensitization in mice. Toxicol. Sci. 80 (2), 310-321.

Vanoirbeek, J.A., Tarkowski, M., Vanhooren, H.M., De Vooght, V., Nemery, B., Hoet P.H., 2006. Validation of a mouse model of chemical-induced asthma using trimellitic anhydride, a respiratory sensitizer, and dinitrochlorobenzene, a dermal sensitizer. J. Allergy Clin. Immunol. 117 (5), 1090-1097.

Wenzel, S., Holgate, S.T., 2006. The mouse trap: it still yields few answers in asthma. Am. J. Respir. Crit. Care Med. 174 (11), 1173-1176. 